\title{
Basic Parameters of Blood Count as Prognostic Factors for Renal Cell Carcinoma
}

\author{
Grzegorz Prokopowicz, Marcin Życzkowski, Krzysztof Nowakowski, \\ Rafał Bogacki, Piotr Bryniarski, and Andrzej Paradysz
}

Department of Urology, School of Medicine with Division of Dentistry in Zabrze, Medical University of Silesia, Katowice, Poland

Correspondence should be addressed to Rafał Bogacki; r.bogacki@poczta.onet.pl

Received 12 August 2016; Revised 18 October 2016; Accepted 14 November 2016

Academic Editor: Maria L. Tornesello

Copyright (C) 2016 Grzegorz Prokopowicz et al. This is an open access article distributed under the Creative Commons Attribution License, which permits unrestricted use, distribution, and reproduction in any medium, provided the original work is properly cited.

\begin{abstract}
Background. Renal cell carcinoma is the most common type of kidney cancer. Taking account of morbidity and mortality increase, it is evident that searching for independent prognostic factors is needed. Aim of the Study. The aim of the study was to analyze routinely performed blood parameters as potential prognostic factors for kidney cancer. Material and Methods. We have retrospectively reviewed the records of 230 patients treated for renal cell carcinoma in the years 2000-2006. Preoperative blood parameters, postoperative histopathological results, and staging and grading were performed. To estimate the risk of tumor recurrence and cancer specific mortality (CSM) within five years of follow-up, uni- and multivariate Cox and regression analyses were used. To assess the quality of classifiers and to search for the optimal cut-off point, the ROC curve was used. Results. T stage of the tumor metastasis is the most important risk factor for early recurrence and cancer specific mortality $(p<0.001)$. The preoperative platelet count (PLT) above $351 \times 10^{3} / \mathrm{uL}(95.3 \% ; 55.1 \%)$ and AUC of $77 \%$ are negative prognostic factors and correlate with increased cancer specific mortality (CSM) during the five-year follow-up $(p<0.001)$. Increased risk of local recurrence was observed for PLT above $243.5 \times 10^{3} / \mathrm{ul}(59 \% ; 88 \%)$ and AUC of $80 \%(p=0.001)$. The opposite was observed in the mean platelets volume (MPV) for cancer specific mortality (CSM). The cut-off point for the MPV was $10.1 \mathrm{fl}(75.4 \% ; 55.1 \%)$ and for the AUC is of $68.1 \%(p=0.047)$. Conclusions. Many analyzed parameters in univariate regressions reached statistical significance and could be considered as potential prognostic factors for ccRCC. In multivariate analysis, only T stage, platelet count (PLT), and mean platelet volume (MPV) correlated with CSM or recurrent ccRCC.
\end{abstract}

\section{Background}

The incidence of kidney cancer has increased in recent years and has now reached about $2-3 \%$ of malignant tumors in adults. Renal cell carcinoma is the third most common cancer of the urinary tract [1-3]. Kidney cancer detected accidentally is found in approximately $1.5 \%$ of cases at autopsy [4]. Over $80 \%$ of all malignant kidney tumors are renal cell carcinoma (RCC). RCC clear cell type (otherwise known as conventional or classic) most commonly originates from the proximal nephron (in over $80 \%$ of cases).

The main treatment modality for renal cancer is surgery. Kidney tumors, in particular RCC tumors, are poorly sensitive to chemotherapy or radiotherapy; only the currently used targeted therapy achieves temporarily stabilizing effect in 30$40 \%$ of cases. Risk factors for kidney cancer include smoking, obesity, diuretics, phenacetin, exposure to cadmium and asbestos, high protein diet, and chronic dialysis.

The main prognostic factors are grade and stage of tumor and cellular anaplasia, tumor histology, the presence of vascular microinvasion, and the content of the genetic material in the cell analyzed by flow and static cytometry (DNA ploidy). Molecular prognostic factors are listed among the prognostic factors; however, their major drawbacks are cost and low availability [5-13].

\section{Aim of the Study}

The following study aims to answer whether preoperative determination of basic blood cell count can be used as a popular and inexpensive prognostic factor in the treatment of renal cell carcinoma limited to the organ. 


\section{Materials and Methods}

The study was retrospective and used the medical records of 397 patients who underwent surgery for kidney tumors in our center in the years 2000-2006. During the five-year follow-up period of all 397 patients operated on, 230 patients with the postoperative diagnosis of nonmetastatic renal cell carcinoma were enrolled in the study. The median followup was 3,98 $\pm 0,99$ years. According to the inclusion criteria of the study, patients with coexisting conditions that may have an impact on the blood morphology parameters were excluded. On the basis of the information gathered, routinely collected blood count parameters at the time of admission to the ward were analyzed. We analyzed the data on histopathological material, histology, TNM, size and location of the tumor removed, and the positive margin in the case of the nephron sparing surgery (NSS). Histopathologic tumor grade was rated according to the three-degree Fuhrman scale. In order to determine the clinical stage, given data were analyzed according to the TNM classification from 2010 .

The studies were an attempt to determine whether any of the tested parameters can be used to assess the prognosis of kidney cancer, so that a group of patients that require special oncological surveillance can be selected. All the information gathered was analyzed in relation to the local recurrence, metastasis, and tumor-specific deaths. Statistical analysis was performed using the program R [R Core Team (2012)]. For determining the risk of metastasis, tumor recurrence, or death within five years, Cox proportional hazards model was used. To assess the quality of the classifier and the search for the optimal cut-off point, ROC (Receiver Operating Characteristic) curve was used as a tool to describe the overall sensitivity and specificity for the variability characteristics of the classifier.

The examination protocol was approved by the Bioethical Commission of the Medical University of Silesia, decision number KNW/0022/KB215/12.

\section{Results}

The study group included 123 men and 107 women. The average age was $60.9 \pm 10.5$ years. Tumor size was $6.8 \pm 4.1 \mathrm{~cm}$. 89 patients underwent nephron sparing surgery (NSS) (mean tumor size was $4.16 \mathrm{~cm}$ ), and 141 patients underwent radical nephrectomy (mean tumor size was $7.9 \mathrm{~cm}$ ). Local recurrence during follow-up occurred in 25 patients (10.8\%) and distant metastases were found in 22 patients (9.5\%). Tumor-specific death was reported in 6 cases after the NSS (2.6\%) and in 43 (18.6\%) after radical nephrectomy. There was an almost identical distribution of neoplastic changes, taking into account the side operated on, 113 in the right and 117 in the left kidney. We also evaluated the anatomical location of the tumor. The most frequently observed tumors were located on the dorsal side of the kidney, followed by the lower and upper pole. In the central part of the kidney, 7 tumors were detected (Figure 1).

The lowest clinical stage, T1, was observed in 112 patients (T1a-48, T1b-64), T2 in 60 patients (T2a-33, T2b-27), and T3

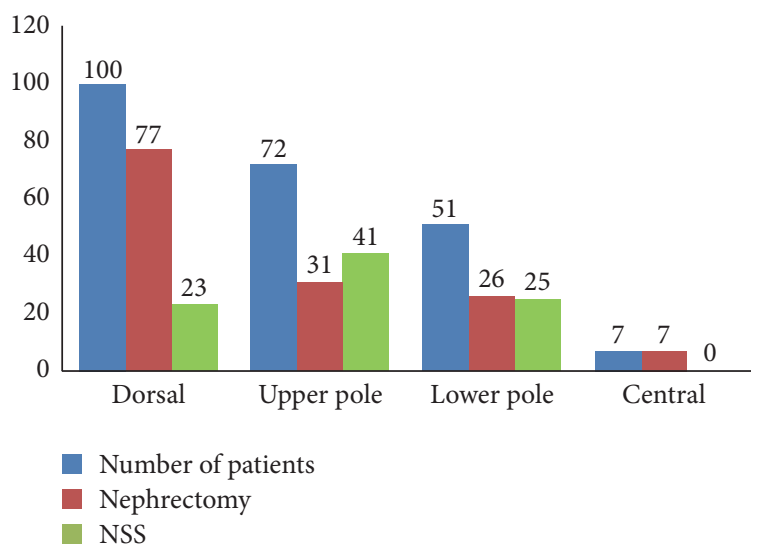

Figure 1: Anatomical location of the tumor according to the performed procedure.

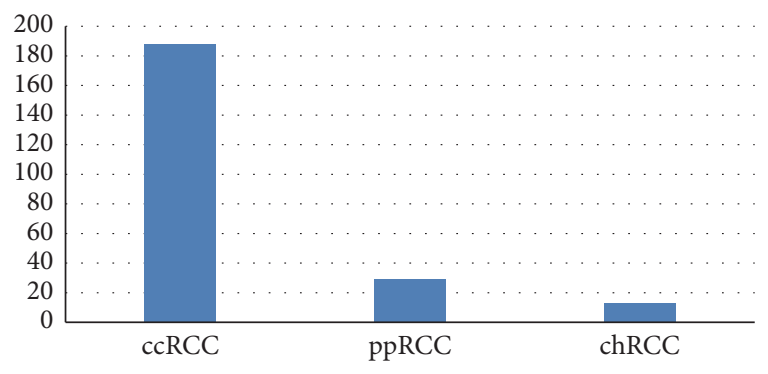

Histological subtypes of RCC

FIGURE 2: Histological subtypes of RCC in the examined group.

in 54 patients (T3a-50, T3b-4), and the most advanced type of cancer, T4, was found in 4 patients.

Histological subtypes of RCC in the examined group are presented in Figure 2.

Average values of the analyzed blood parameters are presented in Table 1.

For determining the risk of metastasis, tumor recurrence, or death, Cox proportional hazards model was used. In this statistical regression, complete and censored data were taken into account. Relatively, the highest number of medical, physical, chemical, and biological risk factors is assigned in this analysis to patients' death, followed by tumor recurrence and metastasis. Statistically significant results $(p<0.05)$ in the univariate model are summarized in Table 2 .

In terms of the impact of a single risk factor, it can be said that the location of the tumor has a strong statistical relationship with the occurrence of metastasis. Cox regression results relating to the location of the tumor in the lower, upper, or dorsal pole compared to the central location are associated with a significant decrease in the risk of metastasis, respectively, $(1-0.096) * 100 \%=90 \%,(1-0.084) * 100 \%=$ $91.6 \%$, and $(1-0.174) * 100 \%=82 \%$. It was also observed that the decline in the value of the studied blood count parameters with the exception of platelet count (PLT) and MPV is an unfavorable prognostic factor $(p<0.05)$. 
TABLE 1: Average values of the analyzed blood parameters.

\begin{tabular}{lcccccccc}
\hline RBC $\left[10^{6} / \mu \mathrm{L}\right]$ & HGB $[\mathrm{g} / \mathrm{dL}]$ & HCT $[\%]$ & MCV [fL] & MCHC [g/dL] & MCH [pg] & RDW [\%] & PLT [10 $/ \mu L]$ & MPV [fL] \\
\hline $4,5 \pm 0,5$ & $13,4 \pm 1,8$ & $39,2 \pm 4,5$ & $87,08 \pm 5,9$ & $34,0 \pm 2,0$ & $30,6 \pm 2,6$ & $14.7 \pm 1.9 \%$ & $249,0 \pm 87,5$ & $11,0 \pm 1,6$ \\
\hline
\end{tabular}

TABLE 2: Univariate Cox regression. Statistically significant parameters predictive of metastasis, recurrence, and death specifically due to renal cell carcinoma.

\begin{tabular}{|c|c|c|c|c|c|c|c|}
\hline $\mathrm{AD}$ & AP & Regression coefficient & SE & $\mathrm{HR}$ & $p$ value & $\mathrm{N}$ & Number of events \\
\hline \multirow{7}{*}{ Metastasis } & NSS/NF & 1,550 & 0,744 & 4,710 & 0,0370 & 230 & 21 \\
\hline & Tumor location C (ref.) & 0,000 & & 1,000 & & 230 & 21 \\
\hline & Location L & $-2,340$ & 0,764 & 0,096 & 0,0022 & & \\
\hline & Location U & $-2,470$ & 0,817 & 0,084 & 0,0025 & & \\
\hline & Location D & $-1,750$ & 0,652 & 0,174 & 0,0073 & & \\
\hline & $\mathrm{T}$ & 0,525 & 0,141 & 1,690 & 0,0002 & 230 & 21 \\
\hline & PLT [thousand $/ \mu \mathrm{L}$ ] & 0,005 & 0,002 & 1,010 & 0,0030 & 230 & 21 \\
\hline \multirow{8}{*}{ Recurrence } & Tumor size $(\mathrm{cm})$ & 0,088 & 0,030 & 1,090 & 0,0027 & 230 & 25 \\
\hline & G & 0,626 & 0,281 & 1,87 & 0,0260 & 230 & 25 \\
\hline & $\mathrm{T}$ & 0,426 & 0,123 & 1,530 & 0,0005 & 230 & 25 \\
\hline & HGB [g/dL] & $-0,397$ & 0,102 & 0,672 & 0,0001 & 230 & 25 \\
\hline & HCT [\%] & $-0,121$ & 0,052 & 0,886 & 0,0200 & 230 & 13 \\
\hline & $\mathrm{MCV}$ [fL] & $-0,113$ & 0,026 & 0,893 & 0,0000 & 230 & 25 \\
\hline & $\mathrm{MCH}[\mathrm{pg}]$ & $-0,196$ & 0,065 & 0,822 & 0,0025 & 230 & 25 \\
\hline & PLT [thousand $/ \mu \mathrm{L}$ ] & 0,008 & 0,001 & 1,010 & 0,0000 & 230 & 25 \\
\hline \multirow{12}{*}{ Death } & $\mathrm{NSS} / \mathrm{NF}$ & 1,280 & 0,436 & 3,600 & 0,0033 & 230 & 49 \\
\hline & Tumor size $(\mathrm{cm})$ & 0,101 & 0,020 & 1,110 & 0,0000 & 230 & 49 \\
\hline & G & 0,704 & 0,202 & 2,020 & 0,0005 & 230 & 49 \\
\hline & $\mathrm{T}$ & 0,510 & 0,089 & 1,670 & 0,0000 & 230 & 49 \\
\hline & HGB [g/dL] & $-0,356$ & 0,077 & 0,700 & 0,0000 & 230 & 49 \\
\hline & HCT [\%] & $-0,114$ & 0,038 & 0,892 & 0,0024 & 230 & 27 \\
\hline & $\mathrm{MCV}$ [fL] & $-0,105$ & 0,019 & 0,900 & 0,0000 & 230 & 49 \\
\hline & $\mathrm{MCHC}[\mathrm{g} / \mathrm{dL}]$ & $-0,148$ & 0,057 & 0,863 & 0,0098 & 230 & 49 \\
\hline & $\mathrm{MCH}[\mathrm{pg}]$ & $-0,206$ & 0,049 & 0,814 & 0,0000 & 230 & 49 \\
\hline & RDW [\%] & 0,155 & 0,056 & 1,170 & 0,0056 & 230 & 49 \\
\hline & PLT [thousand $/ \mu \mathrm{L}$ ] & 0,009 & 0,001 & 1,010 & 0,0000 & 230 & 49 \\
\hline & MPV [fL] & $-0,375$ & 0,093 & 0,687 & 0,0001 & 230 & 49 \\
\hline
\end{tabular}

AE: adverse event; AP: analyzed parameters; HR: hazard ratio; SE: standard error; location C:central location of the tumor; location L: tumor in the lower pole of the kidney; location U: tumor in the upper pole of the kidney; location D: tumor in the dorsal part of the kidney; T: tumor scale; G: Fuhrman scale; PLT: platelets count; HGB: hemoglobin level; HCT: hematocrit; MCV: mean corpuscular volume; MCHC: mean corpuscular hemoglobin concentration; MCH: mean corpuscular hemoglobin; RDW: red blood cell distribution width; MPV: mean platelet volume; NSS: nephron sparing surgery; NF: nephrectomy.

The results of the multivariate Cox regression are summarized in Table 3. Based on this analysis, factors correlated with metastasis have not been found. In this analysis, as in the logistic regression, low predictive value of single blood parameters was revealed. Charts of proportional survival rates of patients according to the number of platelets are presented in Figure 3.

In a Cox multivariate analysis, as in the logistic regression, low predictive value of individual morphology parameters was revealed. Graphs of proportional survival depending on the number and volume of the platelets are shown in Figures 3 and 4.

After analyzing the quality of classifiers (suspected risk factors) in the range of analyzed traits using the ROC curve, there was no statistically significant factor determining the increased risk of metastasis in patients. The number of statistically significant classifiers defining the occurrence of relapse and death is roughly the same. The most likely event is predicting the case of tumor recurrence using the platelet count (PLT). For the cut-off point of 243.5 platelet units (specificity $59 \%$, sensitivity $88 \%$ ), the likelihood of correctly predicting an event is up to $80 \%$ (AUC) (Figure 5). In the case of tumor size (cut-off point of $7.5 \mathrm{~cm}$ ), HGB (cut-off point of $11.6 \mathrm{~g} / \mathrm{dL}$ ), MCV (cut-off point of $86.0 \mathrm{fL}$ ), and $\mathrm{MCH}$ (30.2 pg cut-off point), the likelihood of correctly predicting recurrence within five years of follow-up was $64 \%, 68 \%$, $73 \%$, and $67 \%$, respectively. A similar analysis of potential predictive factors for death was carried out. In this case, we have a $68 \%$ likelihood of occurrence with a cut-off point at $7.5 \mathrm{~cm}$ (specificity $78.9 \%$, sensitivity $49 \%$ ). The best indicator 
TABLE 3: Multivariate Cox regression. Statistically significant parameters predictive of recurrence and death specifically due to renal cell carcinoma.

\begin{tabular}{lccccccc}
\hline AD & AP & Regression coefficient & SE & HR & $p$ value & N & Number of events \\
\hline \multirow{2}{*}{ Recurrence } & $\mathrm{T}$ & 0,288 & 0,129 & 1,334 & 0,0250 & 230 & 25 \\
& PLT [thousand $/ \mu \mathrm{L}]$ & 0,006 & 0,002 & 1,006 & 0,0006 & & \\
\hline \multirow{3}{*}{ Death } & $\mathrm{T}$ & 0,289 & 0,114 & 1,340 & 0,0110 & 230 & \\
& PLT [thousand $/ \mu \mathrm{L}]$ & 0,007 & 0,002 & 1,010 & 0,0000 & & \\
& $\mathrm{MPV}[\mathrm{fL}]$ & $-0,261$ & 0,132 & 0,770 & 0,0470 & \\
\hline
\end{tabular}

AE: adverse event; AP: analyzed parameters; HR: hazard ratio; SE: standard error; T: tumor scale; PLT: platelets count; MPV: mean platelet volume.

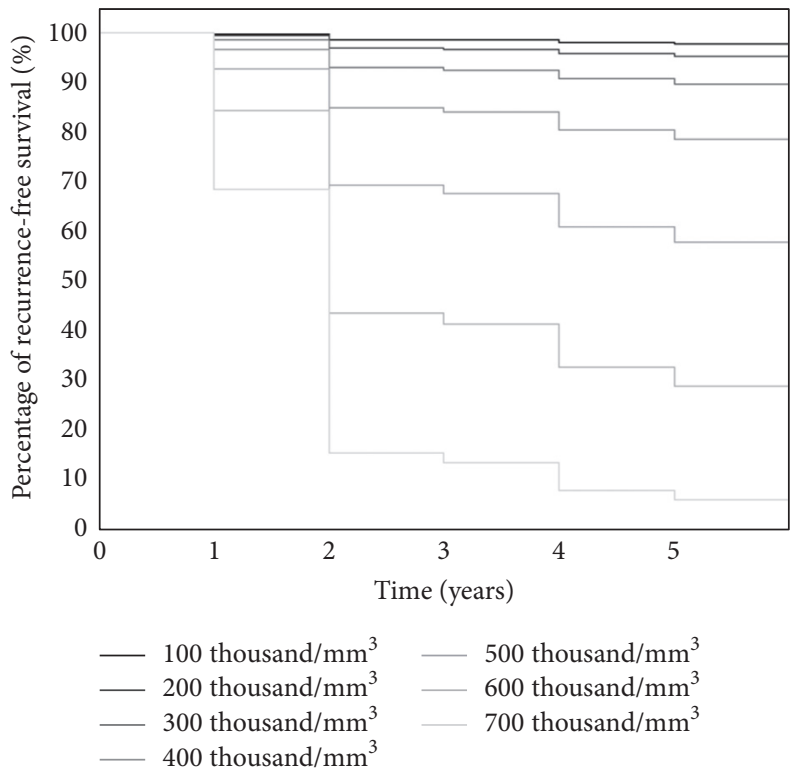

FigurE 3: Estimated recurrence-free survival according to the number of platelets.

in this case appears to be the platelet count. The probability of death within a specific five-year follow-up was $77.7 \%$ at a cut-off point at 351 thousand $/ \mu \mathrm{L}$. The specificity and sensitivity of this classifier are $95.3 \%$ and $55.1 \%$ (Figure 6 ). The worst indicator in terms of predicting mortality is $\mathrm{MCH}$; the likelihood of predicting the correct event using this marker is less than $64 \%$ at a specificity and sensitivity of $77 \%$ and $53 \%$.

\section{Discussion}

Despite advances in medicine, an increase in morbidity and mortality due to kidney cancer is still observed. The diversity of kidney cancers does not enable unambiguous determination of prognosis. Given that $30 \%$ of patients with disease confined to the organ will develop generalized disease after surgical treatment, it is important to search for prognostic factors. Numerous reports of treatment of erythropoietin (EPO) level elevation in patients with renal cancer prompted us to search the potential prognostic factors among blood counts.

An important factor in the tumor environment is hypoxia, which induces tumor cell defense mechanisms. One

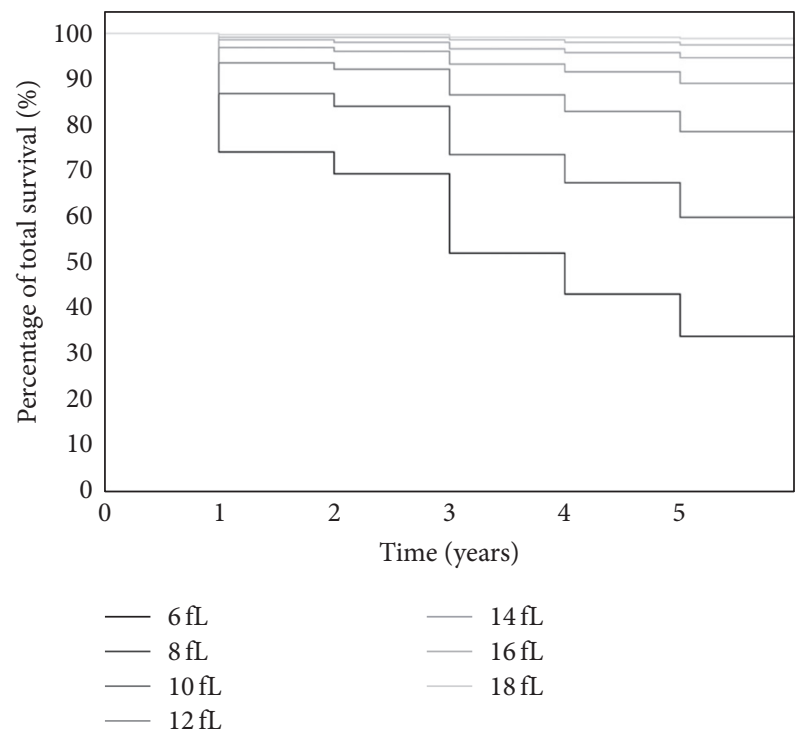

Figure 4: Expected total survival relative to the mean platelet volume.

of these mechanisms is the increase in the transcription of hypoxia inducible factor (HIF) composed of two subunits (HIF- $\alpha$ and HIF- $\beta$ ). High expression of HIF- $\alpha$ subunit is determined mainly by low levels of intracellular oxygen. Under normal oxygenation, the HIF- $\alpha$ subunit is rapidly degraded by normally acting protein VHL (pVHL), forming ubiquitin ligase complex pVHL-E3. In the case of VHL gene mutation, the active inhibitory protein of subunit HIF- $\alpha$ is not produced. This leads to the stabilization and accumulation of HIF- $\alpha$ in cells and contributes to the formation of multiple hypoxia inducible factors that promote angiogenesis, drug resistance, and tumor progression $[14,15]$. One such factor is erythropoietin (EPO). Under normal conditions, the cells of the proximal portion of the coil, from which the clear cell renal carcinoma originates, do not produce detectable amounts of EPO, even under hypoxic conditions. This may explain the importance of VHL gene mutation in the development of clear cell RCC [16, 17]. Erythropoietin is the primary regulator of erythropoiesis in tissues involved in the production of red blood cells. In other tissues, especially in cancer cells, it inhibits apoptosis, stimulates angiogenesis, and promotes cell proliferation. Many studies have confirmed the overexpression of EPO and its receptor (EPOR) in clear 


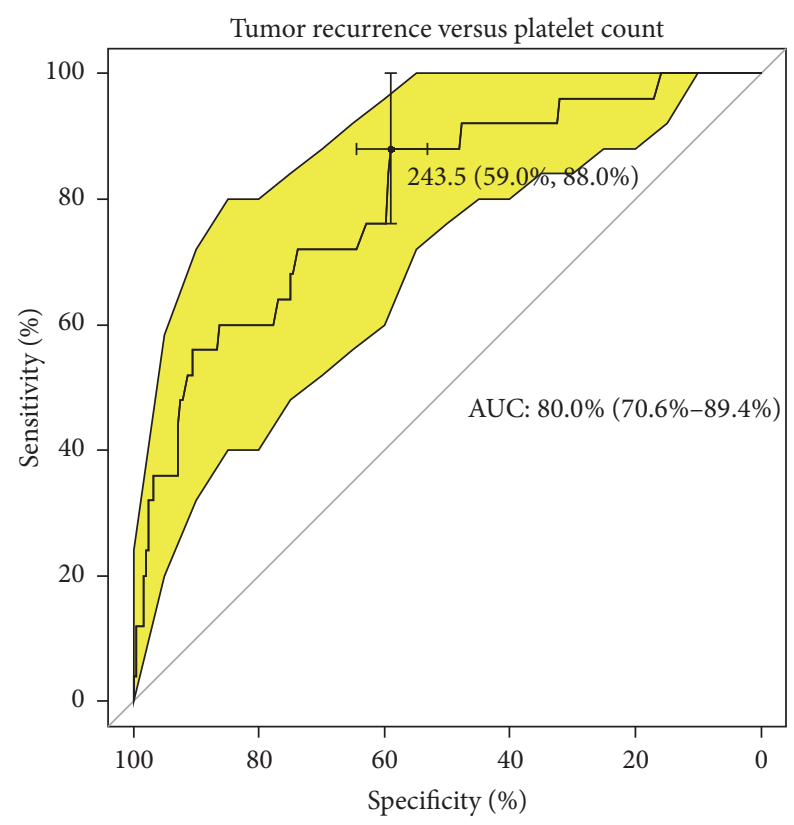

FIGURE 5: Upward sloping quality classifier of tumor recurrence versus platelet count.

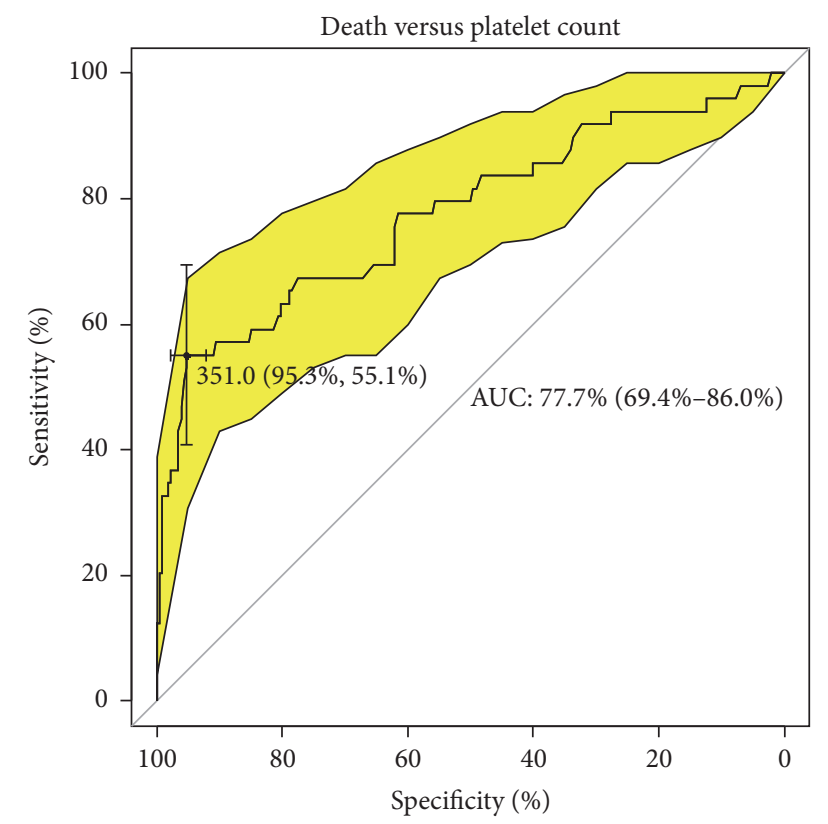

FIgURE 6: Upward sloping classifier of death versus platelet count.

cell renal carcinoma. The prognostic value of this finding merits further investigation [18-20].

If EPO level elevation is observed in patients with renal cell cancer, it would appear that we should watch for polycythemia in these patients. Clinical practice however demonstrates that this is not in fact the case. Despite the increase in the expression of EPO and EPOR, in up to $35 \%$ of patients with RCC, anemia is observed and only 1$5 \%$ of patients develop paraneoplastic polycythemia. Why this happens is not entirely clear. Attempts for explanation include the weak activity of EPO produced by the tumor and the low sensitivity to this factor of the tissues involved in the production of blood. The low level and abnormal iron metabolism may play an important role. The breakdown of tumor cells in the microvessels has also been described. Growth of inflammatory factors and antibodies that occurs during carcinogenesis may contribute to autoimmune hemolysis. Among the preoperative parameters associated with the red blood cells system, the erythrocyte count, hemoglobin, hematocrit, mean corpuscular volume, mean corpuscular hemoglobin concentration, the rate of the average weight of corpuscular hemoglobin, and the coefficient of variation of volume distribution of erythrocytes (anisocytosis) were analyzed in the study. It has been proven that lowering the value of all the above-mentioned parameters except anisocytosis below a specified cut-off point results in an increased risk of tumor-specific death within the five years of follow-up. Reduced preoperative values of HGB, HCT, MCV, and $\mathrm{MCH}$ also predispose patients to early recurrence of cancer. Similar results were also obtained by other authors [21-24].

Our study failed to confirm the prognostic value of hemoglobin concentration in the univariate analyses. Multivariate logistic regression and multivariate Cox proportional hazard model failed to demonstrate a correlation between this factor and tumor recurrence or death or the occurrence of metastases. To date, there are no reports in the literature on the prognostic value of the parameters relating to the construction of red blood cells. Thrombocytosis as a paraneoplastic syndrome is widely described in the literature. Elevated blood platelets may be accompanied by kidney cancer, among other conditions. Thrombocytosis in this case is most likely associated with the neuroendocrine activity of tumor cells. Production of many types of cytokines, including IL-6, IL-11, thrombopoietin, and GM-CSF (granulocyte/macrophage colony stimulating factor), results in increased production of thrombocytes. The main role is played in this case by IL-6, which stimulates platelet production by stimulating the maturation of megakaryocytes [25]. There is evidence on the protective effect of platelets in relation to circulating tumor cells. They hinder their recognition by the immune system and facilitate their integration into the endothelium [26]. Platelets probably also affect tumor growth by producing growth factors such as VEGF, PDGF, hepatocyte growth factor, thrombospondin, or endostatin [27].

In research studies so far, many authors have confirmed that preoperative thrombocytosis is an unfavorable prognostic factor for renal cell carcinoma [28-33].

These reports based on a relatively small number of patients confirm the high value of the platelet count as an independent predictor for renal cell carcinoma. Less enthusiastic towards thrombocytosis and preoperative anemia are Karakiewicz and colleagues, who demonstrated in the single and multivariable analyses that these parameters correlate with the increase of cancer specific mortality. However, the predictive value of these parameters $(0.3 \%)$ is lower than the factors associated with the anatomy of the tumor (TNM, G) or the patient's ECOG scale [34]. Similar conclusions have been shown by German authors [35]. 
Our analyses have shown that the increase in platelet count is a negative prognostic factor in patients undergoing surgery for renal cell carcinoma. Statistical significance was confirmed in the single and multidimensional analyses. In addition, the predictive value of the volume of platelets was confirmed to have statistical significance. The combination of high platelet counts with their small volume is characteristic for cancer diseases. To date, no reports on the predictive value of MPV in renal cancer have been published.

Previous studies looking for new, readily available prognostic factors do not constitute a breakthrough and only improve the predictive value of factors related to tumor stage and anatomy. It is estimated that the parameters of blood count and biochemical parameters may constitute independent prognostic factors for renal cell carcinoma, but they are not qualitatively superior to the TNM classification. It should also be remembered that all the evaluated morphological and biochemical parameters of blood are characterized by low repeatability and are dependent on many factors.

\section{Conclusions}

(1) Low preoperative hemoglobin concentration, hematocrit, average weight of hemoglobin, mean volume, and mean hemoglobin concentration may be considered in the category of risk factors for recurrence and progression of renal cell carcinoma after surgical treatment.

(2) The best predictor among the analyzed preoperative laboratory parameters is the platelet count and volume.

(3) Preoperative platelet count above 243.5 thousand/uL and 351 thousand/uL, respectively, is an independent predictor of recurrence and tumor-specific death during the five years of follow-up.

(4) Preoperative average size of platelets less than $10.1 \mathrm{fL}$ is an independent predictor of tumor-specific mortality during the five-year follow-up.

\section{Competing Interests}

The authors declare that there are no competing interests regarding the publication of this paper.

\section{References}

[1] B. P. Butler, A. C. Novick, D. P. Miller, S. A. Campbell, and M. R. Licht, "Management of small unilateral renal cell carcinomas: radical versus nephron-sparing surgery," Urology, vol. 45, no. 1, pp. 34-40, 1995.

[2] J. K. McLaughlin and L. Lipworth, "Epidemiologic aspects of renal cell cancer," Seminars in Oncology, vol. 27, no. 2, pp. 115123, 2000.

[3] J. H. Lee, C. H. You, G. E. Min et al., "Comparison of the surgical outcome and renal function between radical and nephronsparing surgery for renal cell carcinomas," Korean Journal of Urology, vol. 48, no. 7, pp. 671-676, 2007.
[4] A. Borkowski, "Postępowanie diagnostyczne u chorych z guzami nerek oraz jego wpływ na sposób leczenia," Przewodnik Lekarza, vol. 10, pp. 92-95, 2001.

[5] D. Pascual and A. Borque, "Epidemiology of kidney cancer," Advances in Urology, vol. 2008, Article ID 782381, 7 pages, 2008.

[6] A. Bergström, C.-C. Hsieh, P. Lindblad, C.-M. Lu, N. R. Cook, and A. Wolk, "Obesity and renal cell cancer-a quantitative review," British Journal of Cancer, vol. 85, no. 7, pp. 984-990, 2001.

[7] T. Pischon, P. H. Lahmann, H. Boeing et al., "Body size and risk of renal cell carcinoma in the European Prospective Investigation into Cancer and Nutrition (EPIC)," International Journal of Cancer, vol. 118, no. 3, pp. 728-738, 2006.

[8] S. Weikert, H. Boeing, T. Pischon et al., "Blood pressure and risk of renal cell carcinoma in the European prospective investigation into cancer and nutrition," American Journal of Epidemiology, vol. 167, no. 4, pp. 438-446, 2008.

[9] M. A. Esteban-Barragán, P. Ávila, M. Álvarez-Tejado et al., "Role of the von Hippel-Lindau tumor suppressor gene in the formation of $\beta 1$-integrin fibrillar adhesions," Cancer Research, vol. 62, no. 10, pp. 2929-2936, 2002.

[10] W. M. Linehan, M. M. Walther, and B. Zbar, "The genetic basis of cancer of the kidney," The Journal of Urology, vol. 170, no. 6 I, pp. 2163-2172, 2003.

[11] M. L. Nickerson, M. B. Warren, J. R. Toro et al., "Mutations in a novel gene lead to kidney tumors, lung wall defects, and benign tumors of the hair follicle in patients with the Birt-Hogg-Dubé syndrome," Cancer Cell, vol. 2, no. 2, pp. 157-164, 2002.

[12] C. P. Pavlovich, R. L. Grubb III, K. Hurley et al., "Evaluation and management of renal tumors in the Birt-Hogg-Dubé syndrome," Journal of Urology, vol. 173, no. 5, pp. 1482-1486, 2005.

[13] D. Bodmer, M. Eleveld, M. Ligtenberg et al., "Cytogenetic and molecular analysis of early stage renal cell carcinomas in a family with a translocation $(2 ; 3)(\mathrm{q} 35 ; \mathrm{q} 21)$," Cancer Genetics and Cytogenetics, vol. 134, no. 1, pp. 6-12, 2002.

[14] M. M. Baldewijns, I. J. H. Van Vlodrop, P. B. Vermeulen, P. M. M. B. Soetekouw, M. Van Engeland, and A. P. De Bruïne, "VHL and HIF signalling in renal cell carcinogenesis," Journal of Pathology, vol. 221, no. 2, pp. 125-138, 2010.

[15] M. Ohh, "Ubiquitin pathway in VHL cancer syndrome," Neoplasia, vol. 8, no. 8, pp. 623-629, 2006.

[16] M. S. Wiesener and K.-U. Eckardt, "Erythropoietin, tumours and the von Hippel-Lindau gene: towards identification of mechanisms and dysfunction of oxygen sensing," Nephrology Dialysis Transplantation, vol. 17, no. 3, pp. 356-359, 2002.

[17] M. S. Wiesener, P. Münchenhagen, M. Gläser et al., "Erythropoietin gene expression in renal carcinoma is considerably more frequent than paraneoplastic polycythemia," International Journal of Cancer, vol. 121, no. 11, pp. 2434-2442, 2007.

[18] K. Gong, N. Zhang, K. Zhang, and Y. Na, "The relationship of erythropoietin overexpression with von Hippel-Lindau tumour suppressor gene mutations between hypoxia-inducible factorlalpha and -2alpha in sporadic clear cell renal carcinoma," International Journal of Molecular Medicine, vol. 26, no. 6, pp. 907-912, 2010.

[19] Y.-S. Lee, A. O. Vortmeyer, I. A. Lubensky et al., "Coexpression of erythropoietin and erythropoietin receptor in Von HippelLindau disease-associated renal cysts and renal cell carcinoma," Clinical Cancer Research, vol. 11, no. 3, pp. 1059-1064, 2005. 
[20] G. A. Talmon, "Pure erythropoiesis in clear cell renal cell carcinoma," International Journal of Surgical Pathology, vol. 18, no. 6, pp. 544-546, 2010.

[21] J. M. Fernández Gómez, A. Jalón Monzón, M. Álvarez Múgica, J. García Rodríguez, O. Miranda Aranzubía, and R. C. González Álvarez, "Significance of anemia as an independent prognostic factor in patients with renal cell carcinoma," Medicina Clinica, vol. 133, no. 11, pp. 407-413, 2009.

[22] Y. Komai, K. Saito, K. Sakai, and S. Morimoto, "Increased preoperative serum C-reactive protein level predicts a poor prognosis in patients with localized renal cell carcinoma," $B J U$ International, vol. 99, no. 1, pp. 77-80, 2007.

[23] J. S. Magera Jr., B. C. Leibovich, C. M. Lohse et al., "Association of abnormal preoperative laboratory values with survival after radical nephrectomy for Clinically Confined clear cell renal cell carcinoma," Urology, vol. 71, no. 2, pp. 278-282, 2008.

[24] Y. Choi, B. Park, K. Kim et al., "Erythrocyte sedimentation rate and anaemia are independent predictors of survival in patients with clear cell renal cell carcinoma," British Journal of Cancer, vol. 108, no. 2, pp. 387-394, 2013.

[25] G. Gastl, M. Plante, C. L. Finstad et al., "High IL-6 levels in ascitic fluid correlate with reactive thrombocytosis in patients with epithelial ovarian cancer," British Journal of Haematology, vol. 83, no. 3, pp. 433-441, 1993.

[26] D. Y. C. Heng, W. Xie, M. M. Regan et al., "Prognostic factors for overall survival in patients with metastatic renal cell carcinoma treated with vascular endothelial growth factor-targeted agents: results from a large, multicenter study," Journal of Clinical Oncology, vol. 27, no. 34, pp. 5794-5799, 2009.

[27] H. M. W. Verheul, A. S. Jorna, K. Hoekman, H. J. Broxterman, M. F. B. G. Gebbink, and H. M. Pinedo, "Vascular endothelial growth factor-stimulated endothelial cells promote adhesion and activation of platelets," Blood, vol. 96, no. 13, pp. 4216-4221, 2000.

[28] S. C. O’Keefe, F. F. Marshall, M. M. Issa, M. P. Harmon, and J. A. Petros, "Thrombocytosis is associated with a significant increase in the cancer specific death rate after radical nephrectomy," The Journal of Urology, vol. 168, no. 4, pp. 1378-1380, 2002.

[29] C. Göĝüş, S. Baltaci, E. Filiz, A. Elhan, and Y. Bedük, "Significance of thrombocytosis for determining prognosis in patients with localized renal cell carcinoma," Urology, vol. 63, no. 3, pp. 447-450, 2004.

[30] K. Inoue, K. Kohashikawa, S. Suzuki, M. Shimada, and H. Yoshida, "Prognostic significance of thrombocytosis in renal cell carcinoma patients," International Journal of Urology, vol. 11, no. 6, pp. 364-367, 2004

[31] K. Ito, T. Asano, H. Yoshii, A. Satoh, M. Sumitomo, and M. Hayakawa, "Impact of thrombocytosis and C-reactive protein elevation on the prognosis for patients with renal cell carcinoma," International Journal of Urology, vol. 13, no. 11, pp. 13651370, 2006.

[32] F. Erdemir, M. Kilciler, S. Bedir, Y. Ozgok, H. Coban, and K. Erten, "Clinical significance of platelet count in patients with renal cell carcinoma," Urologia Internationalis, vol. 79, no. 2, pp. 111-116, 2007.

[33] S. Ramsey, G. W. A. Lamb, M. Aitchison, and D. C. McMillan, "Prospective study of the relationship between the systemic inflammatory response, prognostic scoring systems and relapse-free and cancer-specific survival in patients undergoing potentially curative resection for renal cancer," BJU International, vol. 101, no. 8, pp. 959-963, 2008.
[34] P. I. Karakiewicz, Q.-D. Trinh, J. S. Lam et al., "Platelet count and preoperative haemoglobin do not significantly increase the performance of established predictors of renal cell carcinomaspecific mortality," European Urology, vol. 52, no. 5, pp. 1428 1437, 2007.

[35] S. Brookman-May, M. May, V. Ficarra et al., "Does preoperative platelet count and thrombocytosis play a prognostic role in patients undergoing nephrectomy for renal cell carcinoma? Results of a comprehensive retrospective series," World Journal of Urology, vol. 31, no. 5, pp. 1309-1316, 2013. 


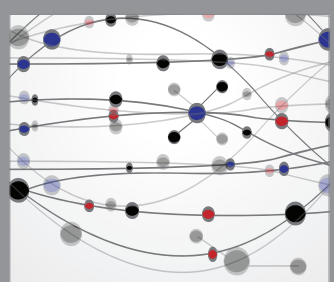

The Scientific World Journal
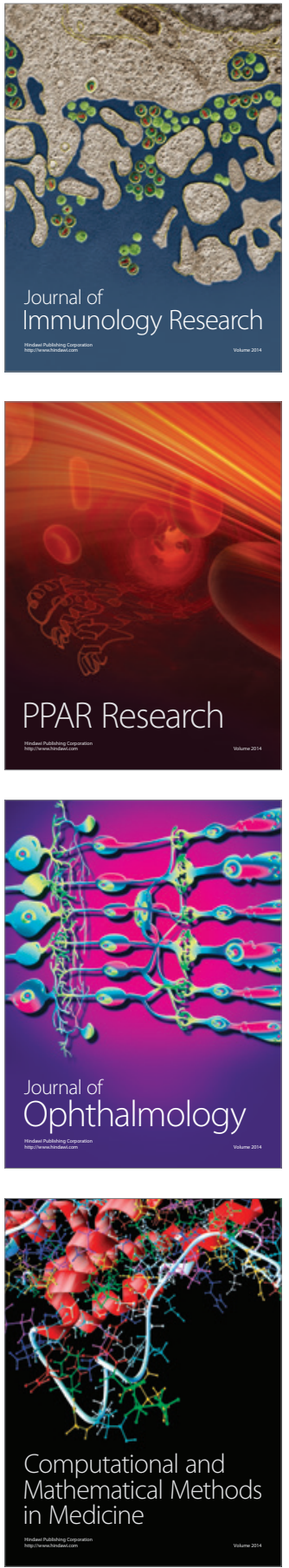

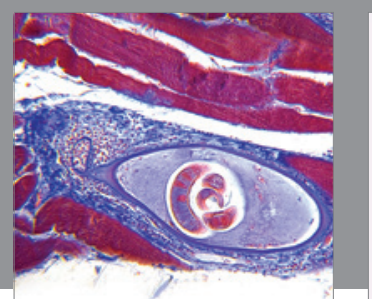

Gastroenterology Research and Practice

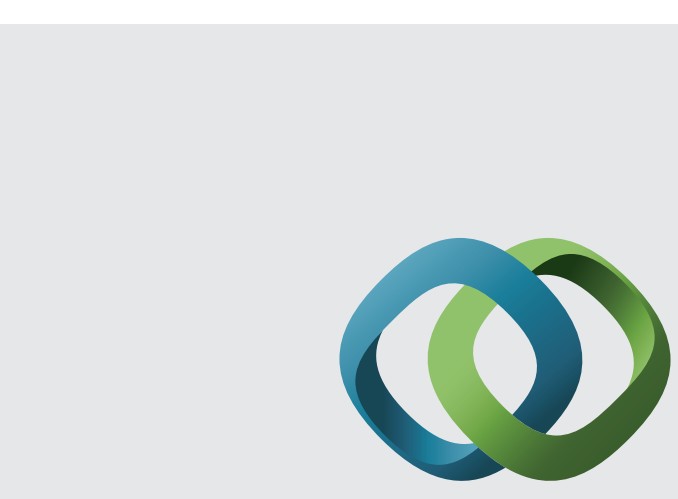

\section{Hindawi}

Submit your manuscripts at

http://www.hindawi.com
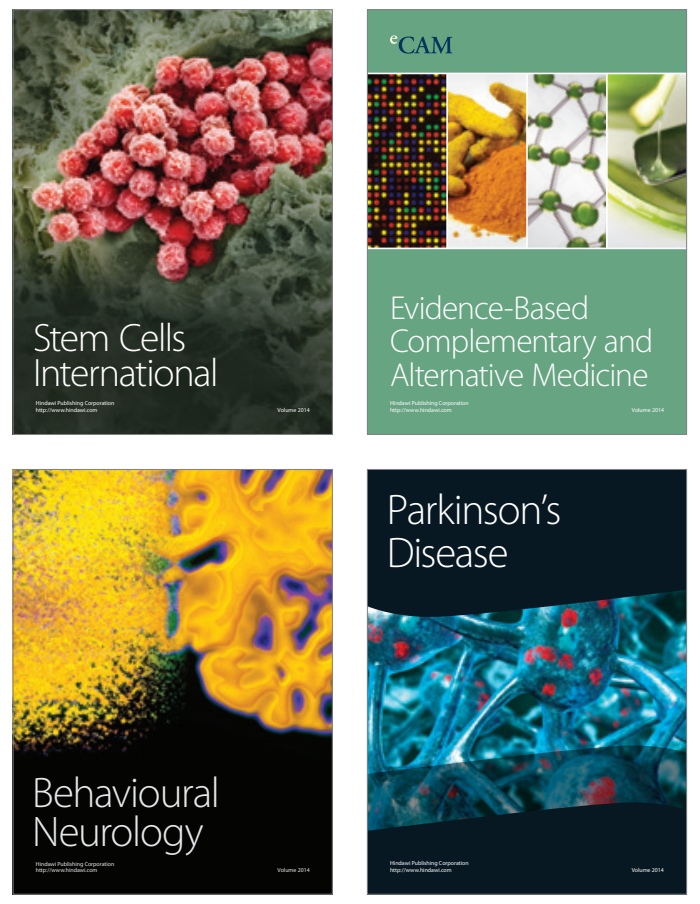
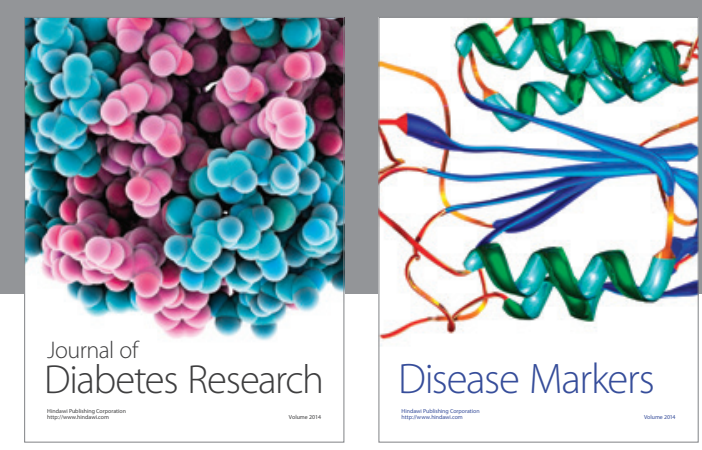

Disease Markers
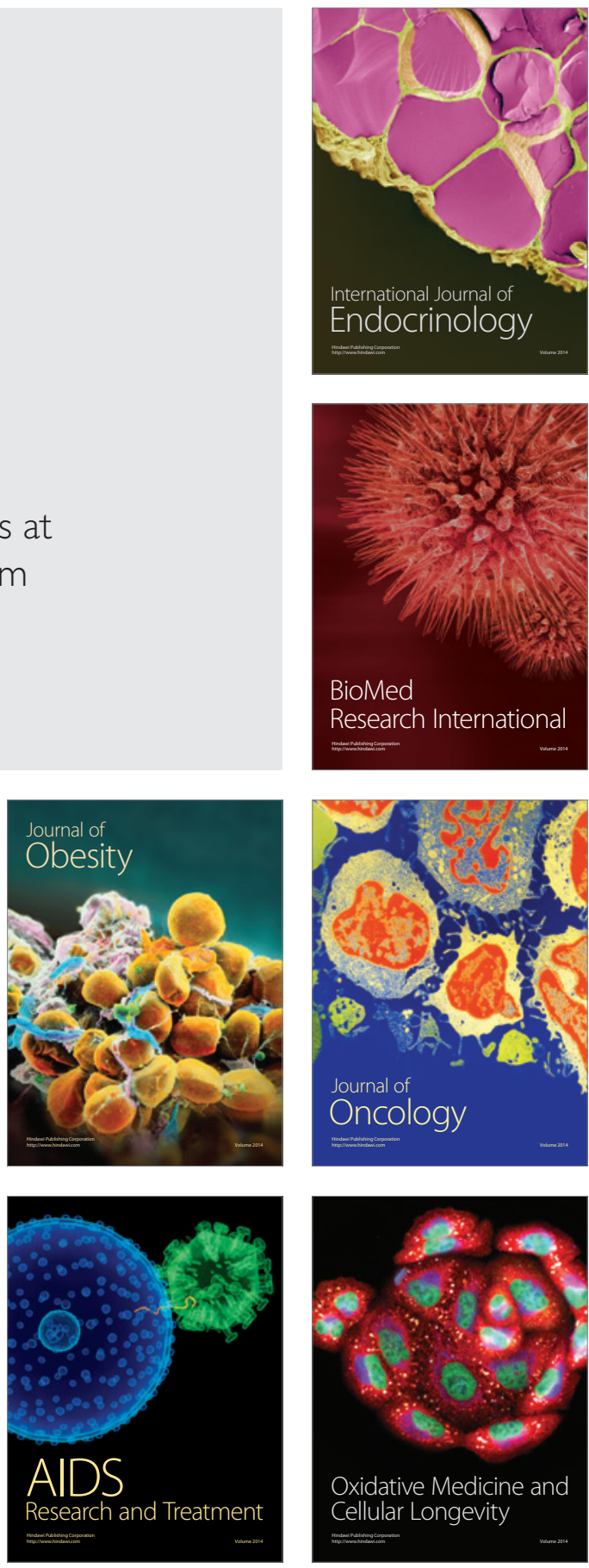